Polymer Journal, Vol. 38, No. 9, pp. 930-939 (2006)

(C) 2006 The Society of Polymer Science, Japan

\title{
Well-Defined Graft Copolymers of Methacrylate, Acrylate, and Styrene via Ruthenium-Catalyzed Living Radical Polymerization
}

\author{
Yu Miura, ${ }^{1}$ Kotaro SAtoh, ${ }^{1}$ Masami Kamigaito, ${ }^{1, \dagger}$ and Yoshio OKamoto ${ }^{2}$ \\ ${ }^{1}$ Department of Applied Chemistry, Graduate School of Engineering, Nagoya University, \\ Furo-cho, Chikusa-ku, Nagoya 464-8603, Japan \\ ${ }^{2}$ EcoTopia Science Institute, Nagoya University, Furo-cho, Chikusa-ku, Nagoya 464-8603, Japan
}

(Received May 15, 2006; Accepted June 3, 2006; Published August 4, 2006)

\begin{abstract}
The ruthenium-catalyzed living radical polymerization was first applied to the synthesis of a series of well-defined graft polymers with the controlled lengths of both the backbone and graft chains. The synthetic method was based on the ruthenium-catalyzed "grafting-from" polymerization of various monomers, such as methacrylate, acrylate, and styrene, from the backbone polymers also obtained via the ruthenium-catalyzed living radical polymerization. The backbone polymer was first synthesized by the ruthenium-catalyzed living radical random copolymerization of methyl methacrylate (MMA) and 2-(trimethylsilyloxy)ethyl methacrylate (TMSHEMA) followed by the in situ transformation of the silyloxyl group into the ester with a $\mathrm{C}-\mathrm{Br}$ bond via direct reaction with the acid bromide (2-bromoisobutyryl bromide). The obtained multifunctional macroinitiator was employed for the ruthenium-catalyzed "grafting-from" radical polymerization of MMA, $n$-butyl acrylate, styrene, and TMSHEMA to afford a series of the graft polymers $\left(M_{\mathrm{w}} / M_{\mathrm{n}} \sim 1.1\right)$ with controlled lengths of the backbone and graft chains. [doi:10.1295/polymj.PJ2006031]

KEY WORDS Graft Polymer / Living Radical Polymerization / Metal Catalyst / Ruthenium / Methacrylate / Acrylate / Styrene / Precision Polymer Synthesis /
\end{abstract}

Radical polymerization is one of the most widely employed methods in industrial polymer synthesis, but usually results in poorly-controlled polymers in terms of the primary structures such as molecular weights, molecular weight distributions (MWDs), and their architectures. However, in recent years, living/ controlled radical polymerizations have been significantly developed to allow the syntheses of various well-defined polymers not only with controlled molecular weights and with defined end-groups, but also with controlled architectures, such as block, graft, and star polymers. These rapidly spreading polymerizations can be mainly categorized into the following three processes: the nitroxide-mediated polymerization (NMP) ${ }^{1-4}$ the metal-catalyzed living radical polymerization or atom transfer radical polymerization (ATRP), ${ }^{5-9}$ and the reversible addition-fragmentation chain transfer (RAFT) polymerization. ${ }^{10}$

Graft copolymers, defined as comb-shaped branched polymers with a number of attached graft chains on the backbone chain, can be generally obtained by three methods, i.e., "grafting-onto," "grafting-from," and "grafting-through" methods. The last two methods are effective for synthesizing well-defined graft polymers when combined with living polymerization. The various living radical polymerizations mentioned above have also been used for the graft copolymer synthesis. ${ }^{11-13}$ The "grafting-through" method, ${ }^{14-21}$ which involves the polymerizations of macromonomers, produced controlled graft copolymers, but often resulted in an incomplete monomer consumption due to the poor reactivity of the macromonomers at higher conversions. ${ }^{21}$ On the other hand, "grafting-from" by living radical polymerizations ${ }^{22-34}$ has been applied as an efficient method to synthesize graft copolymers having various grafting chains. In this method, relatively high molecular weight polymers with multifunctional initiating sites can be used as the backbone chain to produce the high molecular weight graft copolymers. ${ }^{24-30}$ More recently, graft copolymers with controlled molecular weights both in the graft and backbone chains have also been attained by the combination of the living radical polymerizations. ${ }^{32-34}$ Another excellent application of the $\mathrm{Cu}$-mediated ATRP to the "grafting-from" method is the growth of densely grafted chains on a material surface. ${ }^{35-42}$

In this study, we report the synthesis of the graft copolymers with controlled lengths of both the backbone and graft chains via the repeated ruthenium-catalyzed living radical polymerizations (Scheme 1). The ruthenium-catalyzed living radical polymerization is one of the most versatile and controllable systems that can be employed for a wide variety of monomers such as methacrylates, acrylates, and styrenes. The controllability in terms of molecular weights, MWDs, and end-functionality of the halogen group is the most

${ }^{\dagger}$ To whom correspondence should be addressed (E-mail: kamigait@apchem.nagoya-u.ac.jp). 


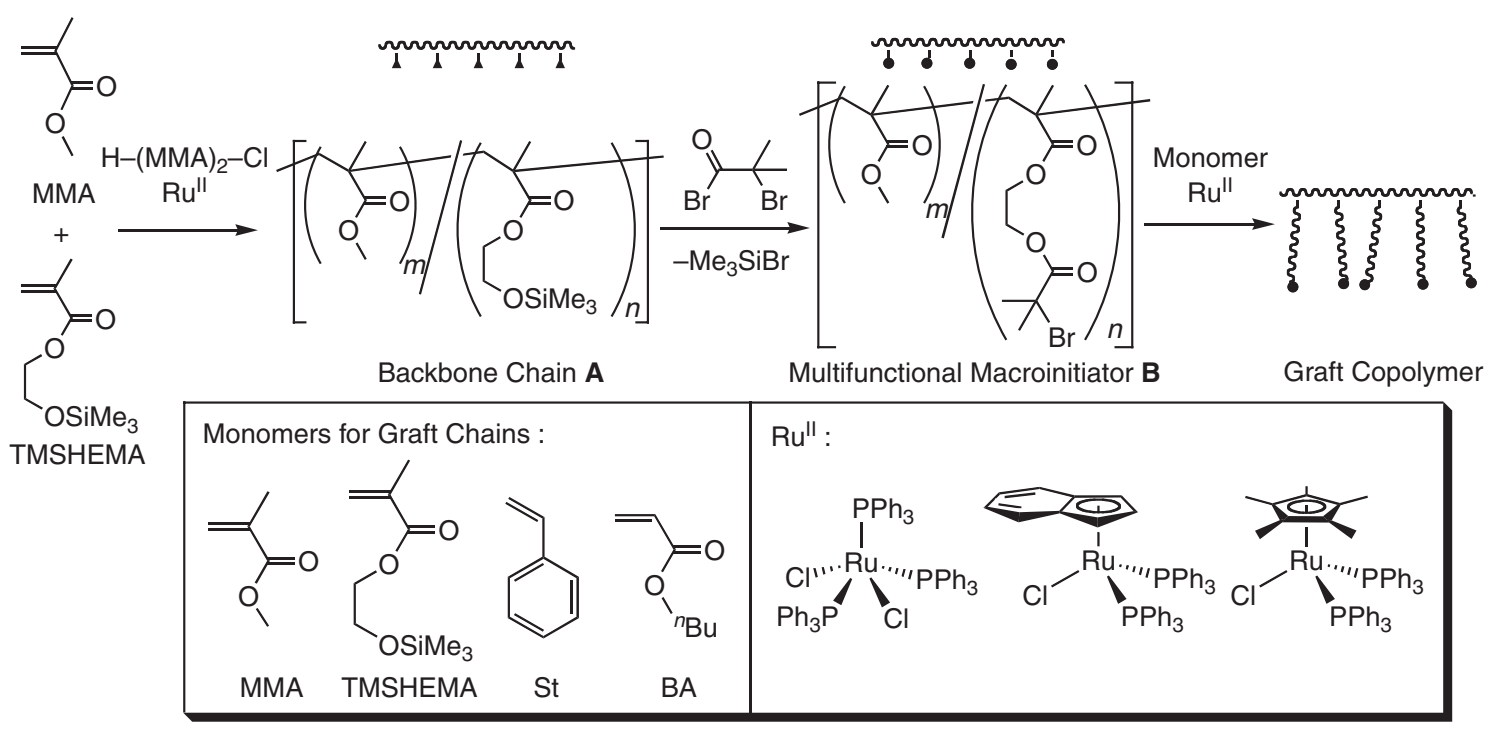

Scheme 1. Graft copolymerization via ruthenium-catalyzed living radical polymerization.

reliable and excellent among the other metal-catalyzed living radical polymerizations. Although the ruthenium-catalyzed polymerization has been used for the synthesis of various end-functionalized, ${ }^{43,44}$ block ${ }^{45}$ and star polymers ${ }^{46-49}$ no applications of the systems to the graft polymer synthesis have been reported.

Thus, we first synthesized poly(methacrylate)s with multifunctional initiating sites and controlled molecular weights via the ruthenium-catalyzed living radical random copolymerization of methyl methacrylate (MMA) and 2-(trimethylsilyloxy)ethyl methacrylate (TMSHEMA), followed by the in situ transformation of the Si-group into the ester with a $\mathrm{C}-\mathrm{Br}$ bond via direct reaction with the acid bromide (2-bromoisobutyryl bromide). We then employed the ruthenium-catalyzed "grafting-from" living radical polymerization of various monomers, such as MMA, TMSHEMA, $n$-butyl acrylate (BA), and styrene (St), for the synthesis of a series of graft copolymers with different types of monomers and controlled chain lengths.

\section{EXPERIMENTAL}

\section{Materials}

MMA (Tokyo Kasei; >99\%) was washed with aq. $\mathrm{NaOH}(5 \%)$ and water, dried over magnesium sulfate, and distilled from calcium hydride under reduced pressure before use. St, BA (both Tokyo Kasei; >99\%) and TMSHEMA (Aldrich; >96\%) were distilled over calcium hydride under reduced pressure before use. $\mathrm{Me}_{2} \mathrm{C}\left(\mathrm{CO}_{2} \mathrm{Me}\right) \mathrm{CH}_{2} \mathrm{C}\left(\mathrm{CO}_{2} \mathrm{Me}\right)(\mathrm{Me}) \mathrm{Cl}$ [H-(MMA) $)_{2}-$ $\mathrm{Cl}]$ as an initiator, was prepared and purified by distillation as reported. ${ }^{50} \mathrm{RuCl}_{2}\left(\mathrm{PPh}_{3}\right)_{3}$, (STREM; >99\%) $\mathrm{Ru}(\mathrm{Ind}) \mathrm{Cl}\left(\mathrm{PPh}_{3}\right)_{2}, \mathrm{Ru}\left(\mathrm{Cp}^{*}\right) \mathrm{Cl}\left(\mathrm{PPh}_{3}\right)_{2}$ (both were donated from Wako Chemicals), $\mathrm{Al}(\mathrm{acac})_{3}$ (acac: acetyl- acetonate), $\mathrm{Al}(\mathrm{O} t-\mathrm{Bu})_{3}$ (both Wako Chemicals; >98\%) were used as received. All metal compounds were handled in a glove box (VAC) under a moisture- and oxygen-free argon atmosphere $\left(\mathrm{H}_{2} \mathrm{O},<1 \mathrm{ppm} ; \mathrm{O}_{2}\right.$, $<1 \mathrm{ppm}$ ). Toluene was distilled from sodium and benzophenone and bubbled with dry nitrogen over $15 \mathrm{~min}$ right before use. $n-\mathrm{Bu}_{3} \mathrm{~N}$ (as an additive), $n$ hexane, and tetralin (as an internal standards for gas chromatographic analysis of the monomers) were distilled from calcium hydride before use. 2-Bromoisobutyryl bromide (BIBB, Aldrich; >98\%) was distilled before use.

\section{Synthesis of the Backbone Chain}

All polymerizations were carried out by syringe technique under dry nitrogen in glass tubes equipped with a three-way stopcock or in baked and sealed glass vials. A typical example for the copolymerization of MMA and TMSHEMA with $\mathrm{H}-(\mathrm{MMA})_{2}-\mathrm{Cl} /$ $\mathrm{Ru}$ (Ind) $\mathrm{Cl}\left(\mathrm{PPh}_{3}\right)_{2} / n$ - $\mathrm{Bu}_{3} \mathrm{~N}$ is given below. In a $50 \mathrm{~mL}$ round-bottomed flask was placed $\mathrm{Ru}(\mathrm{Ind}) \mathrm{Cl}\left(\mathrm{PPh}_{3}\right)_{2}$ $(10 \mathrm{mg}, 0.013 \mathrm{mmol})$, hexane $(0.30 \mathrm{~mL})$, MMA $(1.01$ $\mathrm{mL}, 9.38 \mathrm{mmol})$, TMSHEMA $(0.68 \mathrm{~mL}, 3.12 \mathrm{mmol})$, $\mathrm{H}-(\mathrm{MMA})_{2}-\mathrm{Cl}(0.25 \mathrm{~mL}$ of $509 \mathrm{mM}$ solution in toluene, $0.13 \mathrm{mmol})$ and $n-\mathrm{Bu}_{3} \mathrm{~N}(0.16 \mathrm{~mL}$ of $400 \mathrm{mM}$ solution in toluene, $0.064 \mathrm{mmol}$ ) at room temperature. The total volume of reaction mixture was $6.40 \mathrm{~mL}$. Immediately after mixing, nine aliquots $(0.70 \mathrm{~mL}$ each) of the solutions were injected into backed glass tubes. The reaction vials were sealed and placed in an oil bath kept at $80^{\circ} \mathrm{C}$ under vigorous stirring. In predetermined intervals, the polymerization was terminated by cooling the reaction mixtures to $-78^{\circ} \mathrm{C}$. Monomer conversion was determined by gas chromatography with hexane as an internal standard. The quenched reaction solution was precipitated into hex- 
ane and isolated by centrifugation. After three times of the precipitation, the precipitate was evaporated to dryness to yield the product, which was subsequently dried overnight in vacuo at room temperature.

\section{In Situ Transformation of the Backbone Chain into the Multifunctional Initiator}

An in situ synthetic method of multifunctional macroinitiator $\mathbf{B}$ via direct reaction with the acid bromide is given below. In a $50 \mathrm{~mL}$ round-bottomed flask was synthesized the backbone chain $\mathbf{A}$ as shown above. Directly to the quenched reaction solution was then added 2-bromoisobutyryl bromide $(2.0 \mathrm{~mL}, 16.2$ mmol, 6.0 equiv to the trimethylsilyl unit) at room temperature under stirring for $36 \mathrm{~h}$. The reaction mixture was precipitated into hexane and isolated by centrifugation. After three times of the precipitation, the precipitate was diluted with acetone and precipitated into hexane. The precipitate was then evaporated to dryness to yield the product, which was subsequently dried overnight in vacuo at room temperature.

\section{Ruthenium-Catalyzed "Grafting-from" Copolymeriza- tion of Various Monomers}

A typical example for the graft copolymerization of MMA on the multifunctional macroinitiator $\mathbf{B}$ with $\mathrm{Ru}(\mathrm{Ind}) \mathrm{Cl}\left(\mathrm{PPh}_{3}\right)_{2} / \mathrm{Al}(\mathrm{acac})_{3}$ is given below. In a $50 \mathrm{~mL}$ round-bottomed flask was placed polymer B (75 mg, $0.13 \mathrm{mmol} \mathrm{C}-\mathrm{Br}$ bonds), $\mathrm{Ru}(\mathrm{Ind}) \mathrm{Cl}\left(\mathrm{PPh}_{3}\right)_{2}$ (10 mg, $0.013 \mathrm{mmol}), \mathrm{Al}(\mathrm{acac})_{3}(0.163 \mathrm{~g}, 0.50 \mathrm{mmol})$, hexane $(0.32 \mathrm{~mL})$, and MMA $(0.68 \mathrm{~mL}, 6.30 \mathrm{mmol})$ at room temperature. The total volume of reaction mixture was $12.60 \mathrm{~mL}$. Immediately after mixing, ten aliquots $(1.00 \mathrm{~mL}$ each) of the solutions were injected into backed glass tubes. The reaction vials were sealed and placed in an oil bath kept at $80^{\circ} \mathrm{C}$ under vigorous stirring. In predetermined intervals, the polymerization was terminated by cooling the reaction mixtures to $-78^{\circ} \mathrm{C}$. Monomer conversion was determined by gas chromatography with hexane as an internal standard. The quenched reaction solution was precipitated into methanol and isolated by centrifugation. After three times of the precipitation, the precipitate was evaporated to dryness to yield the product, which was subsequently dried overnight in vacuo at room temperature.

\section{Detachment of Polystyrene Graft Chains from the Backbone}

Prior to the hydrolysis, the graft copolymers were fractionated by preparative SEC to remove a small amount of the higher molecular weight fraction. The fractionated graft copolymer with PSt graft chains $(60 \mathrm{mg})$ was then placed in a $25 \mathrm{~mL}$ round-bottom flask and dissolved in THF $(9.0 \mathrm{~mL})$. After adding
$\mathrm{KOH}$ solution ( $0.3 \mathrm{~g}$ dissolved in $3.0 \mathrm{~mL}$ of methanol), the mixture was heated to $80^{\circ} \mathrm{C}$ for $24 \mathrm{~h}$. The solvent was removed by evaporation, and $6.0 \mathrm{~mL}$ of $\mathrm{CHCl}_{3}$ was added to the remaining solid. The solution was washed with water $(6.0 \mathrm{~mL} \times 3)$. The organic layer was evaporated to dryness to yield the product, which was subsequently dried overnight in vacuo at room temperature to give $50 \mathrm{mg}$ of the detached polystyrene.

\section{Measurements}

The ${ }^{1} \mathrm{H}$ NMR spectra were recorded on a Varian Gemini 2000 spectrometer $(400 \mathrm{MHz})$ in $\mathrm{CDCl}_{3}$ at $50^{\circ} \mathrm{C}$. The number average molecular weights $\left(M_{\mathrm{n}}\right)$ and molecular weight distributions (MWDs: $M_{\mathrm{w}} / M_{\mathrm{n}}$ ) of the polymers were measured by size exclusion chromatography (SEC) using THF at a flow rate 1.0 $\mathrm{mL} / \mathrm{min}$. at $40^{\circ} \mathrm{C}$ on two polystyrene gel columns; both Shodex KF-805 L, that were connected to a JASCO PU-980 precision pump and a JASCO RI-930 detector. The molecular weight was calibrated against seven standard poly(methyl methacrylate) samples $\left(M_{\mathrm{n}}=1,990-6,590,000\right)$ or eight standard polystyrene samples $\left(M_{\mathrm{n}}=526-900,000\right)$. The monomer conversions were determined from the concentration of the residual monomer measured by gas chromatography using hexane or tetralin as the internal standard. The absolute weight-average molecular weight $\left(M_{\mathrm{w}}\right)$ of the polymers was determined by multiangle laser light scattering (MALLS) in tetrahydrofuran (THF) at $40{ }^{\circ} \mathrm{C}$ on Wyatt Technology DAWN DSP photometer $(\lambda=633 \mathrm{~nm})$. The refractive index increment $(\mathrm{d} n / \mathrm{d} c)$ was measured in THF at $25^{\circ} \mathrm{C}$ on Wyatt Optilab rEX refractmeter $(\lambda=633 \mathrm{~nm})$. For example, the $\mathrm{d} n / \mathrm{d} c$ value was $0.103 \mathrm{~mL} / \mathrm{g}$ for the graft polymer of PMMA graft chains.

\section{RESULTS AND DISCUSSION}

Synthesis of Well-Defined Backbone Polymer by Ruthenium-Catalyzed Living Radical Random Copolymerization of MMA and TMSHEMA

The ruthenium-catalyzed living radical polymerization was first employed for the synthesis of the welldefined backbone polymers. For this, we copolymerized MMA and TMSHEMA using two representative ruthenium complexes $\left[\mathrm{RuCl}_{2}\left(\mathrm{PPh}_{3}\right)_{3}\right.$ and $\mathrm{Ru}(\mathrm{Ind}) \mathrm{Cl}$ $\left.\left(\mathrm{PPh}_{3}\right)_{2}\right]$, both of which are effective for the living radical polymerization of methacrylates, ${ }^{5,51}$ to obtain copolymers with the silyloxy-groups in the pendants. The mixture of MMA and TMSHEMA (3:1 molar ratio) was thus polymerized with the two ruthenium complexes in conjunction with $\mathrm{H}-(\mathrm{MMA})_{2}-\mathrm{Cl}$ $\left[\mathrm{Me}_{2} \mathrm{C}\left(\mathrm{CO}_{2} \mathrm{Me}\right) \mathrm{CH}_{2} \mathrm{C}\left(\mathrm{CO}_{2} \mathrm{Me}\right)(\mathrm{Me}) \mathrm{Cl}\right]$ as the initiator in the presence of $n-\mathrm{Bu}_{3} \mathrm{~N}$ in toluene at $80^{\circ} \mathrm{C}$. 


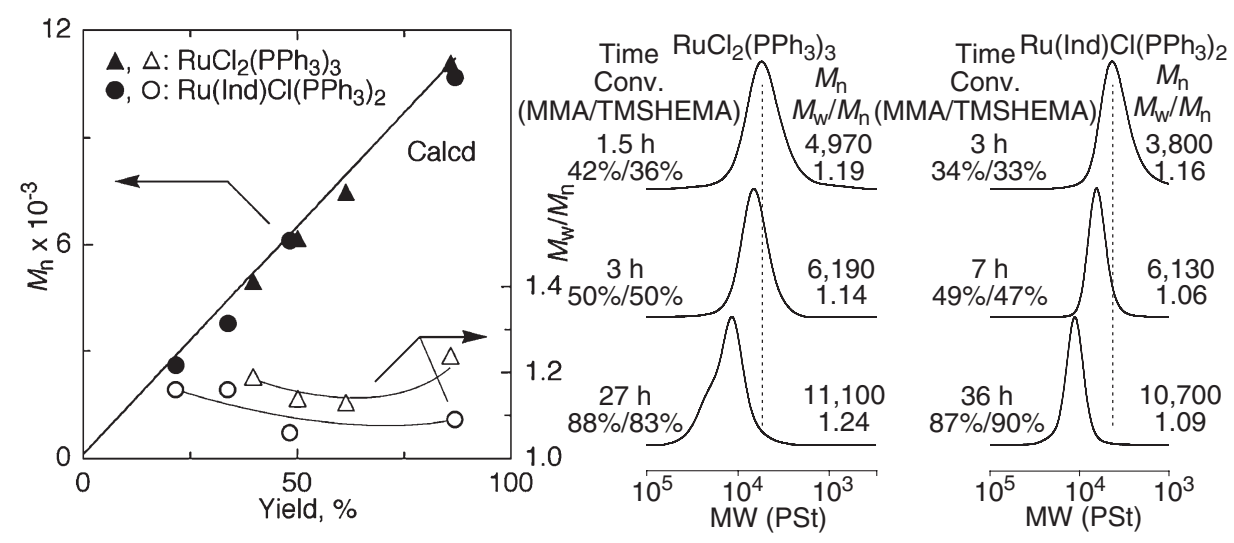

Figure 1. Random copolymerization of MMA and TMSHEMA with $\mathrm{RuCl}_{2}\left(\mathrm{PPh}_{3}\right)_{3}$ or $\mathrm{Ru}(\mathrm{Ind}) \mathrm{Cl}\left(\mathrm{PPh}_{3}\right)_{2}$ in toluene at $80{ }^{\circ} \mathrm{C}$ : $[\mathrm{MMA}]_{0}=1.5 \mathrm{M} ;[\mathrm{TMSHEMA}]_{0}=0.5 \mathrm{M} ;\left[\mathrm{H}-(\mathrm{MMA})_{2}-\mathrm{Cl}\right]_{0}=20 \mathrm{mM},\left[\mathrm{RuCl}_{2}\left(\mathrm{PPh}_{3}\right)_{3}\right]_{0}=10 \mathrm{mM}$ and $\left[n-\mathrm{Bu} \mathrm{NH}_{0}=40 \mathrm{mM}(\boldsymbol{\Delta}, \triangle)\right.$, $\left[\mathrm{Ru}(\mathrm{Ind}) \mathrm{Cl}\left(\mathrm{PPh}_{3}\right)_{2}\right]_{0}=2.0 \mathrm{mM}$ and $\left[n-\mathrm{Bu}_{3} \mathrm{~N}\right]_{0}=10 \mathrm{mM}(\bullet, \bigcirc)$.

Both monomers were smoothly copolymerized at almost the same rate, which shows the random or statistical copolymerization of MMA and TMSHEMA. Figure 1 shows the dependence of the number-average molecular weights $\left(M_{\mathrm{n}}\right)$ of the obtained copolymers on the polymer yield calculated from the conversions of each monomer. With both $\mathrm{RuCl}_{2}\left(\mathrm{PPh}_{3}\right)_{3}$ and $\mathrm{Ru}(\mathrm{Ind}) \mathrm{Cl}\left(\mathrm{PPh}_{3}\right)_{2}$, the $M_{\mathrm{n}}$ increased in direct proportion to the copolymer yield and agreed well with the calculated values assuming that one molecule of the initiator $\left[\mathrm{H}-(\mathrm{MMA})_{2}-\mathrm{Cl}\right]$ generates one living polymer chain. Both series of the SEC curves shifted to a higher molecular weight with the increasing yields. The MWDs were narrow throughout the reaction while they were narrower with $\mathrm{Ru}(\mathrm{Ind}) \mathrm{Cl}\left(\mathrm{PPh}_{3}\right)_{2}$ than with $\mathrm{RuCl}_{2}\left(\mathrm{PPh}_{3}\right)_{3}$. These results indicated that $\mathrm{Ru}$ (Ind) $\mathrm{Cl}\left(\mathrm{PPh}_{3}\right)_{2}$ is more suitable for the synthesis of the well-controlled copolymers of MMA and TMSHEMA similar to the homopolymer of MMA. ${ }^{51}$ Thus, the random copolymer of MMA/TMSHEMA with fairly narrow MWDs $\left(M_{\mathrm{n}}=10,500, M_{\mathrm{w}} / M_{\mathrm{n}}=\right.$ 1.08) was obtained as a precursor of the multifunctional macroinitiator (copolymer A in Scheme 1).

In Situ Transformation of the Silyloxy-Groups into the Ester with $\mathrm{C}-\mathrm{Br}$ Bond via Direct Reaction with the Acid Bromide

The well-defined copolymer A obtained with $\mathrm{Ru}-$ (Ind) $\mathrm{Cl}\left(\mathrm{PPh}_{3}\right)_{2}$ was then converted into the multifunctional macroinitiator $\mathbf{B}$. The already reported transformation method mainly for the copper-mediated ATRP included two steps: first, the trimethylsilyl groups were deprotected into the hydroxyl form by $\mathrm{KF}$ and $n-\mathrm{Bu}_{4} \mathrm{NF}$, and then the esterification by an acid bromide with a $\mathrm{C}-\mathrm{Br}$ bond. ${ }^{16-19}$ Considering that the trimethylsilyl halide is a good leaving group, we investigated the direct transformation of the trimethylsilyl groups into the brominated esters just by adding the carboxylic acid bromide $\left[\mathrm{Me}_{2} \mathrm{C}(\mathrm{Br}) \mathrm{COBr}\right]$ in situ into the polymerization mixture without using the deprotection process (see the experimental section).

Figure 2 shows the ${ }^{1} \mathrm{H}$ NMR spectra of the backbone copolymers before and after the transformation with 2-bromoisobutyryl bromide (A and B, respectively). In the spectrum of copolymer A (Figure 2A), there were characteristic signals derived from the MMA and TMSHEMA units; i.e., the $\alpha$-methyl $(f)$ and main-chain methylene protons $(e)$ for both units, the methoxy groups $(g)$ for the MMA units, the methylene $(a$ and $b)$ and trimethylsilyl groups $(c)$ for the TMSHEMA units. The MMA/TMSHEMA composition $(75 / 25)$, obtained from the peak intensity ratio ( $g$ vs. $a+b)$, was in good agreement with the calculated values from the monomer feed ratios and the gas chromatographic conversions of each monomer $(73 / 27)$.

The transformation was carried out with an excess amount of 2-bromoisobutyryl bromide at r.t. for $24 \mathrm{~h}$. After the transformation, the ${ }^{1} \mathrm{H}$ NMR spectrum of the copolymers exhibited typical changes (Figure 2B). The signal of the trimethylsilyl groups completely disappeared ( $c$ in Figure 2A). The $a$ and $b$ peaks shifted toward a lower magnetic field (peaks $a^{\prime}$ and $b^{\prime}$, respectively) along with the appearance of an additional peak attributed to the methyl groups adjacent to the $\mathrm{C}-\mathrm{Br}$ bonds $(d)$. The unit ratio of MMA and the introduced brominated ester groups $(75 / 25)$ agreed well with the ratio of MMA/TMSHEMA in copolymer $\mathbf{A}$ before the transformation. This indicates that the macroinitiator $\mathbf{B}$ with multi-initiating sites on the side groups was successfully derived by the direct in situ transformation of the trimethylsilyl groups. This method is simpler than the reported one because the two steps, i.e., the isolation of the polymer from the polymerization mixture and the deprotection of the silyl groups, can be omitted. 


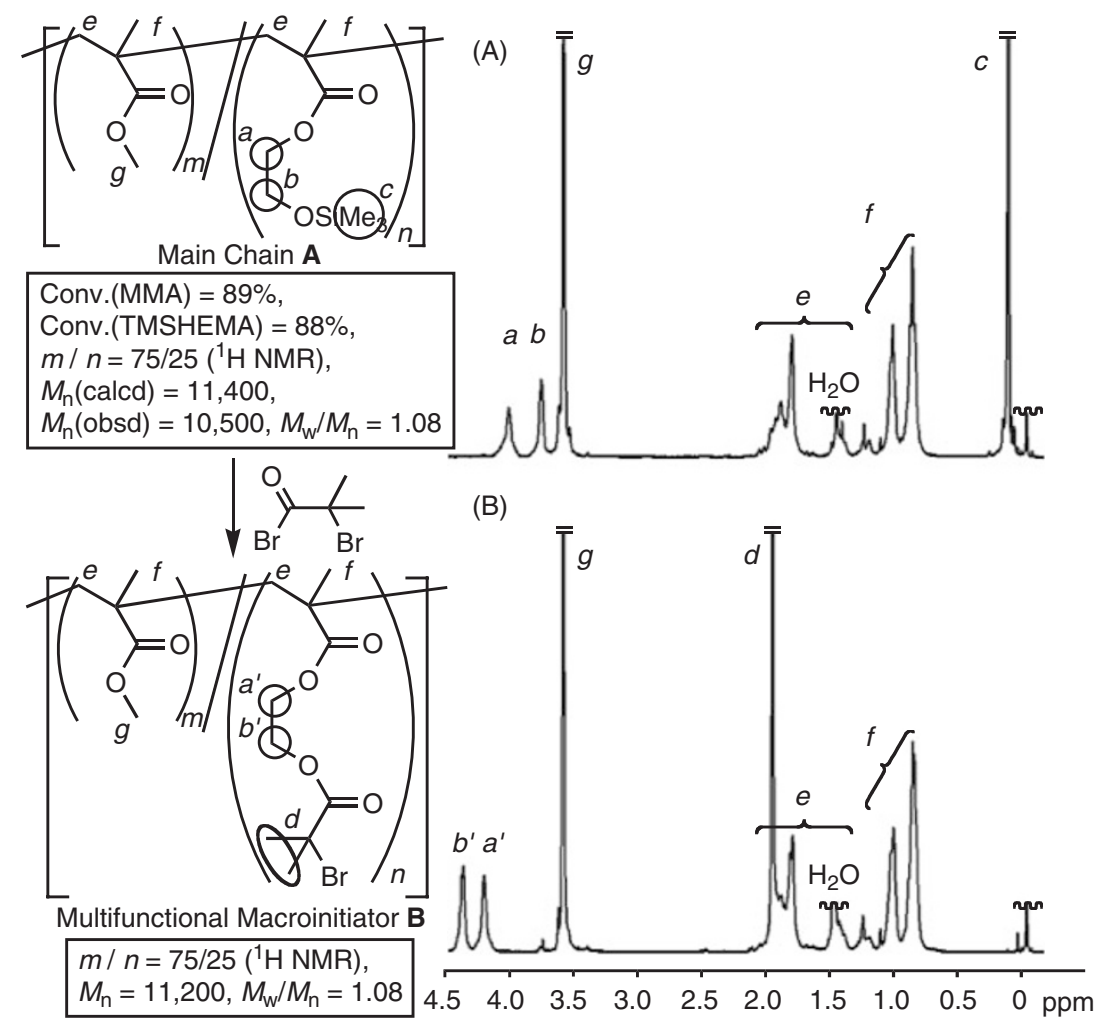

Figure 2. ${ }^{1} \mathrm{H} \mathrm{NMR}$ spectra (in $\mathrm{CDCl}_{3}$ at $50^{\circ} \mathrm{C}$ ) of before (A) and after (B) transformation of trimethylsilyloxyl groups in the backbone $\mathbf{A}$.

\section{Ruthenium-Catalyzed Grafting-from Copolymeriza- tion of Various Monomers}

The multifunctional macroinitiator $\mathbf{B}$ was then employed for the graft polymerization of MMA in conjunction with $\mathrm{Ru}(\mathrm{Ind}) \mathrm{Cl}\left(\mathrm{PPh}_{3}\right)_{2}$ in toluene at $80^{\circ} \mathrm{C}$ in the presence of a series of additives, such as $n$ $\mathrm{Bu}_{3} \mathrm{~N}, \mathrm{Al}(\mathrm{O} t-\mathrm{Bu})_{3}$, and $\mathrm{Al}(\mathrm{acac})_{3}$, which are effective for enhancing the rate and the controllability of the Ru-catalyzed living radical polymerization. ${ }^{46,51}$

The graft polymerization of MMA smoothly proceeded with the macroinitiator $\mathbf{B} / \mathrm{Ru}$-system in the presence of these additives, while the graft polymerization did not reach quantitative monomer conversion $(<50 \%)$. With all the additives, the SEC curves of the obtained polymers shifted to higher molecular weights (Figure 3). However, the polymers obtained with $n-\mathrm{Bu}_{3} \mathrm{~N}$ showed a broader MWD $\left(M_{\mathrm{w}} / M_{\mathrm{n}}=\right.$ 1.53) and a shoulder in the high molecular region, indicating some intermolecular recombination between the graft chains in the highly active $\mathrm{Ru}(\mathrm{Ind}) \mathrm{Cl}$ $\left(\mathrm{PPh}_{3}\right)_{2} / n-\mathrm{Bu}_{3} \mathrm{~N}$ system. ${ }^{52}$ As for the aluminum additives, $\mathrm{Al}(\mathrm{acac})_{3}$ produced polymers with unimodal and narrow MWDs $\left(M_{\mathrm{n}}=82,500, M_{\mathrm{w}} / M_{\mathrm{n}}=1.16\right)$. In contrast, the polymers obtained with $\mathrm{Al}(\mathrm{O} t-\mathrm{Bu})_{3}$ resulted in a bimodal distribution at the later stage of the polymerization though the main peaks were relatively narrow $\left(M_{\mathrm{n}}=61,600, M_{\mathrm{w}} / M_{\mathrm{n}}=1.12\right)$. This is due to the detachment of the graft chain via trans-

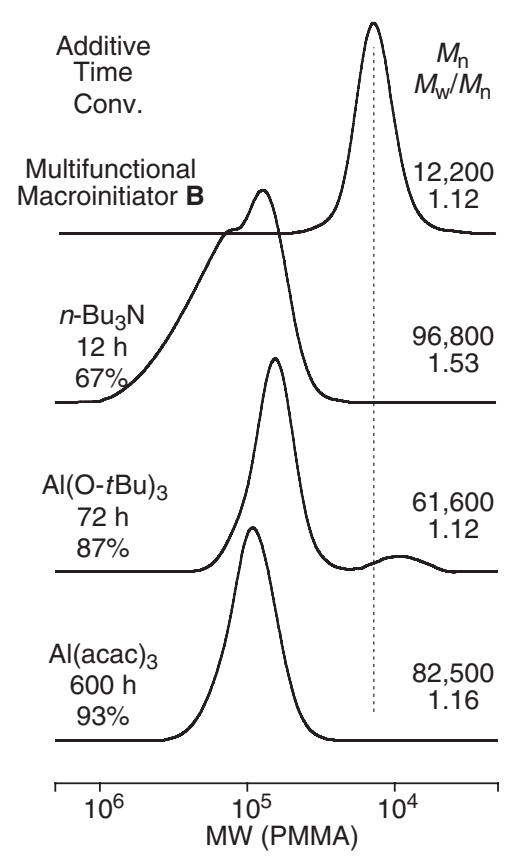

Figure 3. Graft polymerization of MMA from the multifunctional macroinitiator $\mathbf{B}$ in toluene at $80^{\circ} \mathrm{C}$. $[\mathrm{MMA}]_{0}=2.0 \mathrm{M}$; $[\mathrm{C}-\mathrm{Br} \text { bonds in the macroinitiator } \mathbf{B}]_{0}=10 \mathrm{mM}$; $[\mathrm{Ru}(\mathrm{Ind}) \mathrm{Cl}-$ $\left.\left(\mathrm{PPh}_{3}\right)_{2}\right]_{0}=1.0 \mathrm{mM} ;$ [additive $]_{0}=40 \mathrm{mM}$.

esterification between the ester-linkage of the initiating site and $\mathrm{Al}(\mathrm{O} t-\mathrm{Bu})_{3}{ }^{46}$ Thus, the graft polymerization of MMA from the multifunctional macroinitiator 


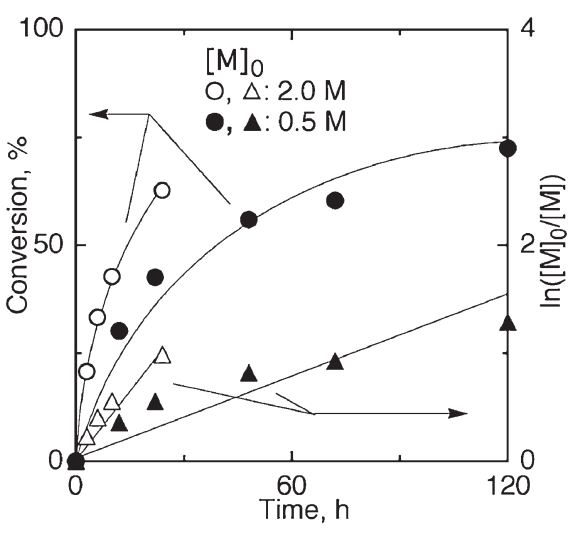

Figure 4. Graft polymerization of MMA from the multifunctional macroinitiator $\mathbf{B}$ in toluene at $80{ }^{\circ} \mathrm{C}$. $[\mathrm{MMA}]_{0}=2.0 \mathrm{M}(\mathrm{O}$ : conversion), $\triangle$ : first-order plot) or $0.5 \mathrm{M}(\bullet$ : conversion, $\boldsymbol{\Delta}$ : firstorder plot); $[\mathrm{C}-\mathrm{Br} \text { bonds in the macroinitiator } \mathbf{B}]_{0}=10 \mathrm{mM}$; $\left[\mathrm{Ru}(\mathrm{Ind}) \mathrm{Cl}\left(\mathrm{PPh}_{3}\right)_{2}\right]_{0}=1.0 \mathrm{mM} ;\left[\mathrm{Al}(\mathrm{acac})_{3}\right]_{0}=40 \mathrm{mM}$.

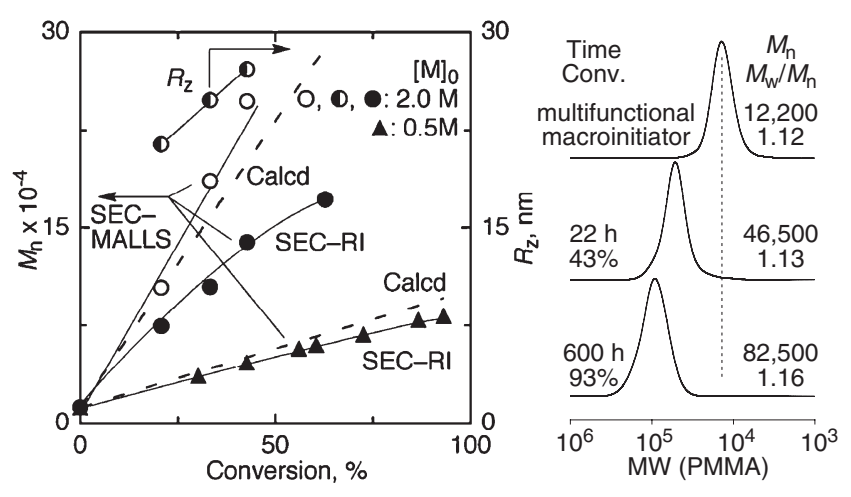

Figure 5. $M_{\mathrm{n}}, M_{\mathrm{w}} / M_{\mathrm{n}}$, and MWD curves of graft copolymer obtained with macroinitiator $\mathbf{B} / \mathrm{Ru}(\mathrm{Ind}) \mathrm{Cl}\left(\mathrm{PPh}_{3}\right)_{2} / \mathrm{Al}(\mathrm{acac})_{3}$ in toluene at $80^{\circ} \mathrm{C}$. $[\mathrm{MMA}]_{0}=2.0 \mathrm{M}\left(\bullet: M_{\mathrm{n}}(\mathrm{SEC}-\mathrm{RI}), \bigcirc\right.$ : $\left.M_{\mathrm{n}}(\mathrm{SEC}-\mathrm{MALLS}), \boldsymbol{\odot}: R_{\mathrm{z}}\right)$ or $0.5 \mathrm{M}\left(\boldsymbol{\Delta}: M_{\mathrm{n}}(\mathrm{SEC}-\mathrm{RI})\right) ;[\mathrm{C}-\mathrm{Br}$ bonds in the macroinitiator $\mathbf{B}]_{0}=10 \mathrm{mM} ;\left[\mathrm{Ru}(\mathrm{Ind}) \mathrm{Cl}\left(\mathrm{PPh}_{3}\right)_{2}\right]_{0}=$ $1.0 \mathrm{mM} ;\left[\mathrm{Al}(\mathrm{acac})_{3}\right]_{0}=40 \mathrm{mM}$.

B was successfully induced by the combination of $\mathrm{Ru}(\mathrm{Ind}) \mathrm{Cl}\left(\mathrm{PPh}_{3}\right)_{2}$ and $\mathrm{Al}(\mathrm{acac})_{3}$.

Figure 4 shows typical examples of the Ru-catalyzed graft polymerization of MMA with the multifunctional macroinitiator $\mathbf{B}$ in the presence of $\mathrm{Al}(\mathrm{acac})_{3}$ in toluene at $80^{\circ} \mathrm{C}$, where the monomer concentration was varied $\left([\mathrm{MMA}]_{0}=0.5\right.$ or $\left.2.0 \mathrm{M}\right)$. Both the graft polymerizations proceeded smoothly. The first-order kinetic plots were almost linear, indicating almost no significant irreversible termination during the polymerization.

Figure 5 shows the $M_{\mathrm{n}}$ and the SEC curves of the graft polymers of MMA obtained using the $\mathrm{Ru}(\mathrm{Ind})$ $\mathrm{Cl}\left(\mathrm{PPh}_{3}\right)_{2} / \mathrm{Al}(\mathrm{acac})_{3}$ initiating system for various initial monomer concentrations $\left([\mathrm{MMA}]_{0}=2.0\right.$ or $0.5 \mathrm{M}$ ). During the early stage of the polymerizations, the $M_{\mathrm{n}}$ values (filled circles and triangles), based on a PMMA standard calibration, increased in direct proportion to the monomer conversion and were close to the calculated values assuming that one molecule of $\mathbf{B}$ generates one molecule of the graft polymer. The MWDs were also unimodal and relatively narrow $\left(M_{\mathrm{w}} / M_{\mathrm{n}}<1.2\right)$. As the polymerization proceeded, however, the increase in the $M_{\mathrm{n}}$ leveled off in both cases. Especially, at a higher monomer concentration, the $M_{\mathrm{n}}$ of the polymer became lower than the calculated values.

The molecular weight and the mean radius of gyration $\left(R_{\mathrm{z}}\right)$ of the graft polymer was then measured by SEC equipped with multiangle laser light-scattering (MALLS) and a refractive index as a dual detector. The $M_{\mathrm{n}}$ (open circles) calculated from the absolute molecular weights $\left(M_{\mathrm{w}}\right)$ by MALLS agreed well with the calculated values throughout the reactions. These results indicated that the hydrodynamic volumes of the graft polymers are quite different from those of the linear polymers due to their branched structures and that the graft chains efficiently grew from the multi-initiating site of $\mathbf{B}$. The $R_{\mathrm{z}}$ values (half-filled circles) slightly increased with the monomer conversion. Furthermore, it is also notable that the controlled graft copolymerization reached a high monomer conversion $(>90 \%)$ without any remarkable recombination.

To further demonstrate the wide feasibility of the ruthenium-catalyzed "grafting-from" radical polymerization, other monomers, such as TMSHEMA, St, and BA, were employed with the multifunctional macroinitiator $\mathbf{B}$ in the presence of the ruthenium complexes (Figure 6). A functional methacrylate, TMSHEMA, was polymerized with the $\mathrm{Ru}(\mathrm{Ind}) \mathrm{Cl}-$ $\left(\mathrm{PPh}_{3}\right)_{2} / \mathrm{Al}(\mathrm{acac})_{3}$ initiating system to give the copolymers with narrow MWDs $\left(M_{\mathrm{w}} / M_{\mathrm{n}}<1.2\right)$ even at a very high conversion ( $90 \%)$ (Figure $6 \mathrm{~B})$. The trimethylsilyloxyl groups in the graft chains can be converted into the hydroxyl functions that produce the hydrophilic grafts.

The graft copolymerization of BA was successfully done with $\mathrm{Ru}\left(\mathrm{Cp}^{*}\right) \mathrm{Cl}\left(\mathrm{PPh}_{3}\right)_{2}$ in place of $\mathrm{Ru}(\mathrm{Ind}) \mathrm{Cl}-$ $\left(\mathrm{PPh}_{3}\right)_{2}$ to provide narrow MWDs $\left(M_{\mathrm{n}}=113,000\right.$, $M_{\mathrm{w}} / M_{\mathrm{n}}=1.09$ ) (Figure 6C) because the former has proven more effective for acrylate polymerization with narrow MWDs. ${ }^{53,54}$ The $M_{\mathrm{n}}$ of the obtained PMMA$g$-PBA determined by SEC-MALLS $\left(M_{\mathrm{n}}=182,000\right)$ was also close to the calculated $M_{\mathrm{n}}$ value from the gas chromatographic conversions $\left[M_{\mathrm{n}}(\mathrm{calcd})=\right.$ 202,000]. The graft copolymerization of another type of vinyl monomer, St, with $\mathrm{Ru}(\mathrm{Ind}) \mathrm{Cl}\left(\mathrm{PPh}_{3}\right)_{2}$ / $\mathrm{Al}(\mathrm{O} t-\mathrm{Bu})_{3}$ resulted in narrow MWDs $\left(M_{\mathrm{n}}=68,900\right.$, $M_{\mathrm{w}} / M_{\mathrm{n}}=1.12$ ) (Figure 6D) though a small fraction of higher molecular weight products was observed as a shoulder of the main peak due to some intermolecular coupling reactions. Thus, the ruthenium-catalyzed "grafting-from" living radical polymerization was effective in producing well-controlled graft copolymers 


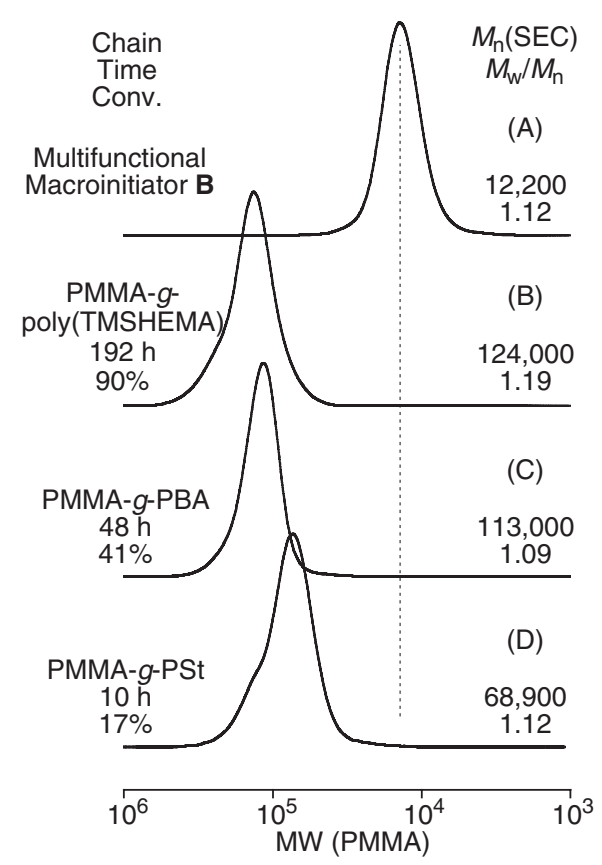

Figure 6. Graft copolymerization of (B) TMSHEMA, (C) $\mathrm{BA}$, and (D) St from (A) the multifunctional macroinitiator $\mathbf{B}$ in toluene at $80^{\circ} \mathrm{C}$. Conditions; TMSHEMA: [TMSHEMA $]_{0}=$ $0.5 \mathrm{M}$; [C-Br bonds in the macroinitiator $\mathbf{B}]_{0}=10 \mathrm{mM}$; $[\mathrm{Ru}(\mathrm{Ind})-$ $\left.\mathrm{Cl}\left(\mathrm{PPh}_{3}\right)_{2}\right]_{0}=1.0 \mathrm{mM} ;\left[\mathrm{Al}(\mathrm{acac})_{3}\right]_{0}=40 \mathrm{mM}$. BA: $[\mathrm{BA}]_{0}=4.0$ $\mathrm{M}$; $[\mathrm{C}-\mathrm{Br} \text { bonds in the macroinitiator } \mathbf{B}]_{0}=20 \mathrm{mM}$; $\left[\mathrm{Ru}\left(\mathrm{Cp}^{*}\right)-\right.$ $\left.\mathrm{Cl}\left(\mathrm{PPh}_{3}\right)_{2}\right]_{0}=2.0 \mathrm{mM} ;\left[n-\mathrm{Bu}_{3} \mathrm{~N}\right]_{0}=10 \mathrm{mM}$. St: $[\mathrm{St}]_{0}=2.0 \mathrm{M}$; $[\mathrm{C}-\mathrm{Br} \text { bonds in the macroinitiator } \mathbf{B}]_{0}=10 \mathrm{mM}$; $[\mathrm{Ru}(\mathrm{Ind})-$ $\left.\mathrm{Cl}\left(\mathrm{PPh}_{3}\right)_{2}\right]_{0}=0.5 \mathrm{mM} ;\left[\mathrm{Al}(\mathrm{Ot}-\mathrm{Bu})_{3}\right]_{0}=20 \mathrm{mM}$.

consisting of various grafts derived from methacrylate, acrylate, styrene, and functionalized monomers by the judicious combination of ruthenium complexes and additives depending on the monomer.

To confirm the graft copolymerization of these monomers, the obtained graft copolymers were analyzed by ${ }^{1} \mathrm{H}$ NMR spectroscopy. Figure 7 shows the ${ }^{1} \mathrm{H}$ NMR spectra of the original multifunctional macroinitiator B (A), a graft polymer with the MMAgrafts (B) and the BA-grafts (C). After the graft polymerizations, the ${ }^{1} \mathrm{H}$ NMR spectra of the copolymers exhibited typical absorptions of these monomers in addition to the original base polymers (Figures 7B and $7 \mathrm{C} v s .7 \mathrm{~A})$. The signals of the methyl $(c)$ and methylene $(a$ and $b)$ peaks of the original bromoester groups shifted toward a higher magnetic field, which indicates the initiation of the graft copolymerization from these groups. In Figure 7C, the additional peaks were assignable to the $n$-butyl ester protons $(g-l)$, and the unit ratio of MMA on the backbone chain and BA on the graft chains (10/90) agreed well with the calculated ratio from the gas chromatographic conversions (10/90). These results support the fact that the obtained graft copolymers contain these monomer units at the expected levels in the graft chains.
Analysis of Graft Chains by Detachment from the Backbone

In the graft copolymers thus far prepared, the graft chains should be connected to the main chain via the ester linkages that can be hydrolyzed into the main and arm chains. To confirm the molecular weights and MWDs of these graft chains, hydrolysis of the ester linkages in the graft copolymer of PMMA- $g$ PSt was carried out using potassium hydroxide in a mixture of methanol and tetrahydrofuran $(1 / 3 \mathrm{v} / \mathrm{v})$ at $80{ }^{\circ} \mathrm{C}$ (Scheme 2). ${ }^{47}$

Figure 8 shows the SEC curves of the polymers obtained before and after the hydrolysis along with the macroinitiator $\mathbf{B}$. After the hydrolysis, the SEC curves shifted toward lower molecular weights $\left(M_{\mathrm{n}}=4,890\right)$ with relatively narrow MWDs $\left(M_{\mathrm{w}} / M_{\mathrm{n}}=1.33\right)$, indicating that the grafted PSt chains were detached from the backbone PMMA chains and that the PSt grafts had the controlled molecular weights. ${ }^{47}$ The higher polydispersity index of the detached polymers than that of the graft polymers is due to that the molecular weight is lower for the former and that the differences in the molecular weights are statistically diminished in the graft polymers that are schematically obtained by connecting the graft chains together on the backbone polymers. The initiation efficiency $(f)$ in the graft copolymerization was calculated from the ratio of the $M_{\mathrm{n}}(\mathrm{SEC})$ of the detached chain to the calculated value assuming that each initiating site forms one graft chain. The high initiation efficiency, $f=85 \%$, supports the rapid initiation in comparison to the propagation in the graft polymerization.

Figure 9 shows the ${ }^{1} \mathrm{H}$ NMR spectra of the polymers obtained after the hydrolysis. After the hydrolysis, the polymers exhibited the typical signals of PSt; i.e., main-chain aliphatic protons ( $b$ and $c$ ) and aromatic protons $(d)$. In addition to these large absorptions, small signals due to the end groups appeared at $1.0 \mathrm{ppm}$, which were assignable to the $\alpha$-methyl groups at the terminal derived from the brominated esters of the initiating site. The molecular weight calculated by the ratio of the aromatic protons $(d)$ to the methyl protons $(a)$ at the end group $\left[M_{\mathrm{n}}(\mathrm{NMR})=\right.$ $4,530]$ is close to that of the SEC $\left[M_{\mathrm{n}}(\mathrm{SEC})=4,890\right]$. These results also indicate that the graft copolymerization with the ruthenium-catalyzed system proceeded in a living manner from the initiating sites in the backbone chain.

\section{CONCLUSIONS}

A series of well-defined graft copolymers with controlled molecular weights in both the backbone and graft chains were prepared via the rutheniumcatalyzed living radical polymerizations. The back- 


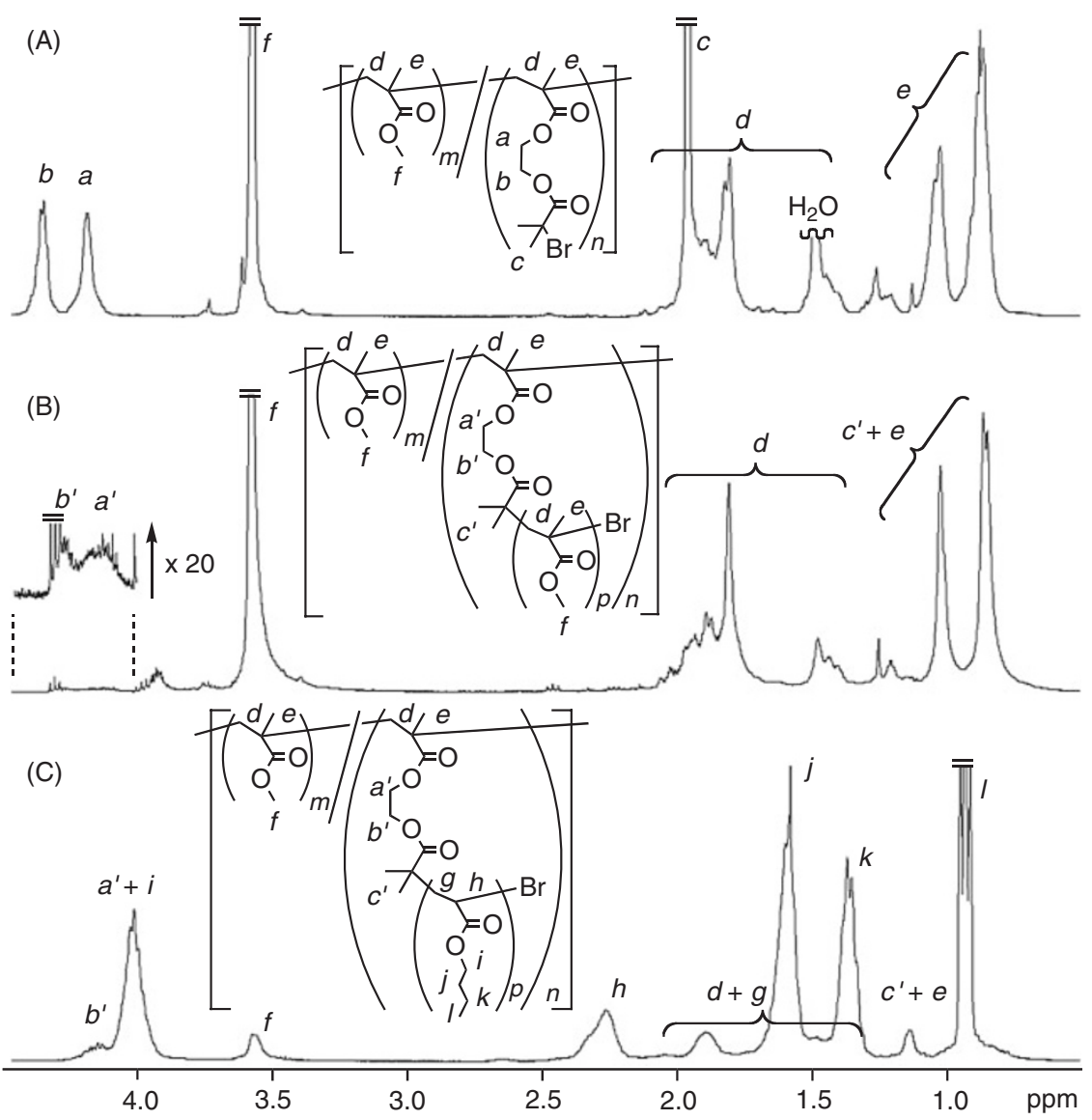

Figure 7. ${ }^{1} \mathrm{H}$ NMR spectra (in $\mathrm{CDCl}_{3}$ at $50{ }^{\circ} \mathrm{C}$ ) of (A) original multifunctional macroinitiator $\mathbf{B}$, (B) graft copolymer of MMA, and (C) $\mathrm{BA}$ as the side chains.

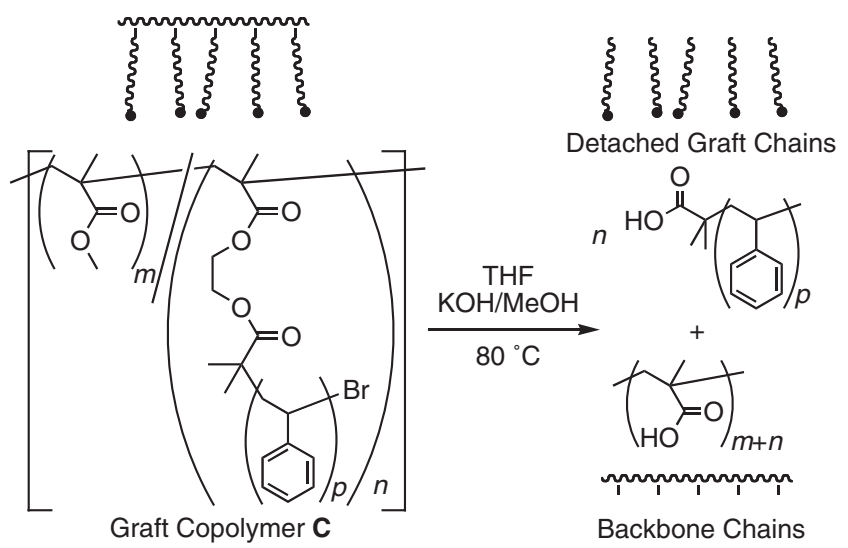

Scheme 2. Detachment of PSt graft chains from the PMMA backbone chains.

bone chain was synthesized by the ruthenium-catalyzed living radical copolymerization of MMA and TMSHEMA and was directly transformed into the macroinitiator with multi-initiating sites of $\mathrm{C}-\mathrm{Br}$ bonds on the side groups. The macroinitiator was further employed for the ruthenium-catalyzed graft copolymerization of various monomers, such as methacrylate, acrylate, and styrene, resulting in the graft copolymers $\left(M_{\mathrm{w}} / M_{\mathrm{n}} \sim 1.1\right)$ with controlled graft chain lengths.

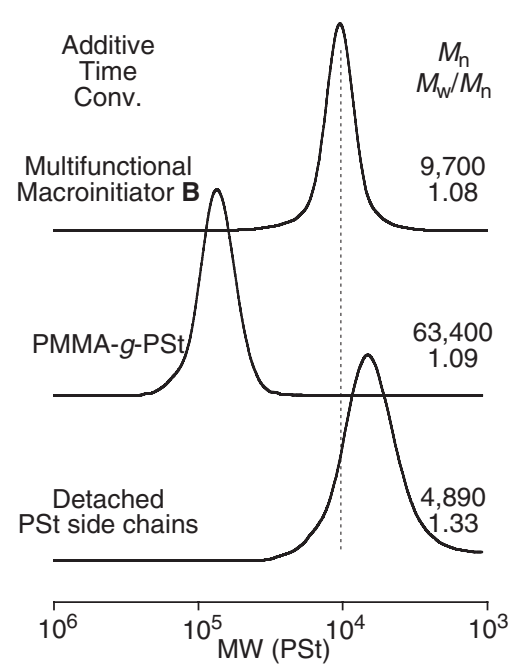

Figure 8. SEC curves of original multifunctional macroinitiator $\mathbf{B}$ (top), graft copolymer of St on the macroinitiator $\mathbf{B}$ in toluene at $80^{\circ} \mathrm{C}$ after fractionation; $[\mathrm{St}]_{0}=2.0 \mathrm{M}$; $[\mathrm{C}-\mathrm{Br}$ bonds in the macroinitiator $\mathbf{B}]_{0}=10 \mathrm{mM}$; $\left[\mathrm{Ru}(\mathrm{Ind}) \mathrm{Cl}\left(\mathrm{PPh}_{3}\right)_{2}\right]_{0}=0.5 \mathrm{mM}$; $\left[\mathrm{Al}(\mathrm{O} t-\mathrm{Bu})_{3}\right]_{0}=20 \mathrm{mM}$ (middle), and hydrolyzed PSt graft chains (bottom).

Acknowledgment. This work was supported in part by the 21st Century COE Program "Nature-Guided Materials Processing", the Ogasawara Foundation 


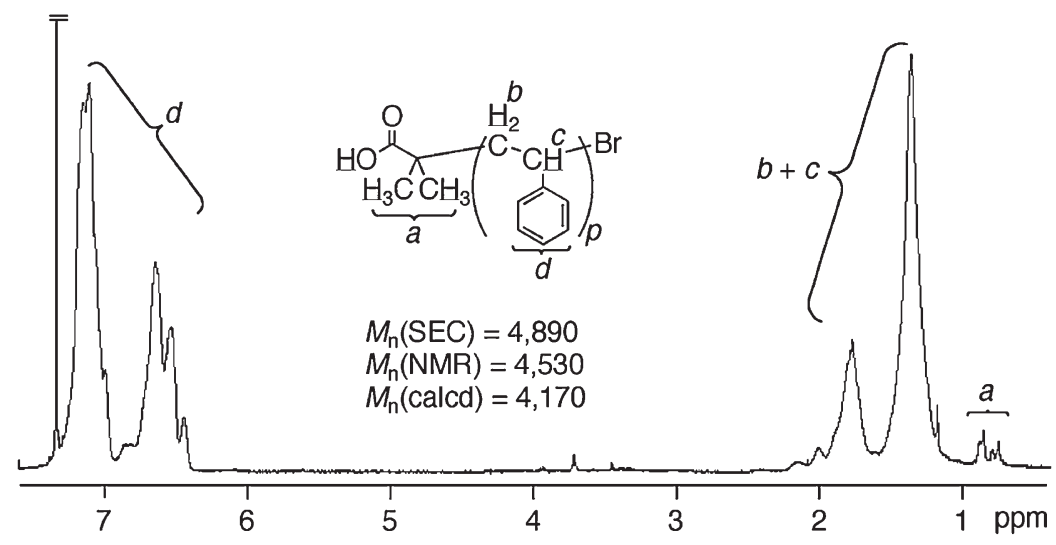

Figure 9. ${ }^{1} \mathrm{H}$ NMR spectrum (in $\mathrm{CDCl}_{3}$ at $50{ }^{\circ} \mathrm{C}$ ) of hydrolyzed PSt graft chains.

for the Promotion of Science \& Engineering, Iketani Science and Technology Foundation, and Izumi Science and Technology Foundation.

\section{REFERENCES}

1. M. K. Georges, R. P. N. Veregin, P. M. Kazmaier, and G. K. Hamer, Macromolecules, 26, 2987 (1993).

2. M. K. Georges, R. P. N. Veregin, P. M. Kazmaier, and G. K. Hamer, Trends. Polym. Sci., 2, 66 (1994).

3. C. J. Hawker, J. Am. Chem. Soc., 116, 11185 (1994).

4. C. J. Hawker, A. W. Bosman, and E. Harth, Chem. Rev., 101, 3661 (2001).

5. M. Kato, M. Kamigaito, M. Sawamoto, and T. Higashimura, Macromolecules, 28, 1721 (1995).

6. M. Kamigaito, T. Ando, and M. Sawamoto, Chem. Rev., 101, 3689 (2001).

7. M. Kamigaito, T. Ando, and M. Sawamoto, Chem. Rec., 4, 3661 (2004).

8. J.-S. Wang and K. Matyjaszewski, J. Am. Chem. Soc., 117, 5614 (1995).

9. K. Matyjaszewski and J. Xia, Chem. Rev., 101, 2921 (2001).

10. J. Chiefari, Y. K. (B.) Chong, F. Ercole, J. Krstina, J. Jeffery, T. P. T. Le, R. T. A. Mayadunne, G. F. Meijs, C. L. Moad, G. Moad, E. Rizzardo, and S. H. Thang, Macromolecules, 31, 5559 (1998).

11. For reviews, see: 11-13. K. A. Davis and K. Matyjaszewski, Adv. Polym. Sci., 159, 1 (2002).

12. H. G. Börner and K. Matyjaszewski, Macromol. Symp., 177, 1 (2002).

13. A. Bhattacharya and B. N. Misra, Prog. Polym. Sci., 29, 767 (2004).

14. H. Mori and A. H. E. Müller, Prog. Polym. Sci., 28, 1403 (2003).

15. Y. Cai, M. Hartenstein, and A. H. E. Müller, Macromolecules, 37, 7484 (2004).

16. S. G. Roos, A. H. E. Müller, and K. Matyjaszewski, Macromolecules, 32, 8331 (1999).

17. H. Shinoda, K. Matyjaszewski, L. Okrasa, M. Mierzwa, and T. Pakula, Macromolecules, 36, 4772 (2003).

18. D. Neugebauer, Y. Zhang, T. Pakula, S. S. Sheiko, and K. Matyjaszewski, Macromolecules, 36, 6746 (2003).
19. D. Neugebauer, M. Theis, T. Pakula, G. Wegner, and K. Matyjaszewski, Macromolecules, 39, 584 (2006).

20. D. M. Haddleton, S. Perrier, and S. A. F. Bon, Macromolecules, 33, 8246 (2000).

21. K. Yamada, M. Miyazaki, K. Ohno, T. Fukuda, and M. Minoda, Macromolecules, 32, 290 (1999).

22. G. Cheng, A. Böker, M. Zhang, G. Krausch, and A. H. E. Müller, Macromolecules, 34, 6883 (2001).

23. C. Li, N. Gunari, K. Fischer, A. Janshoff, and M. Schmidt, Angew. Chem., Int. Ed., 43, 1101 (2004).

24. K. L. Beers, S. G. Gaynor, K. Matyjaszewski, S. S. Sheiko, and M. Möller, Macromolecules, 31, 9413 (1998).

25. H. G. Börner, K. L. Beers, K. Matyjaszewski, S. S. Sheiko, and M. Möller, Macromolecules, 34, 4375 (2001).

26. H. G. Börner, D. Duran, K. Matyjaszewski, M. da Silva, and S. S. Sheiko, Macromolecules, 35, 3387 (2002).

27. S. Qin, K. Matyjaszewski, H. Xu, and S. S. Sheiko, Macromolecules, 36, 605 (2003).

28. S. J. Lord, S. S. Sheiko, I. LaRue, H.-I. Lee, and K. Matyjaszewski, Macromolecules, 37, 4235 (2004).

29. B. S. Sumerlin, D. Neugebauer, and K. Matyjaszewski, Macromolecules, 38, 702 (2005).

30. H. Lee, K. Matyjaszewski, S. Yu, and S. S. Sheiko, Macromolecules, 38, 8264 (2005).

31. Y. Miura, Y. Isobe, T. Nakamura, M. Sugiura, and Y. Okamoto, Polym. J., 37, 617 (2005).

32. R. B. Grubbs, C. J. Hawker, J. Dao, and J. M. J. Fréchet, Angew. Chem., Int. Ed., 36, 270 (1997).

33. R. Venkatesh, L. Yajjou, C. E. Koning, and B. Klumperman, Macromol. Chem. Phys., 205, 2161 (2004).

34. N. Khelfallah, N. Gunari, K. Fischer, G. Gkogkas, N. Hadjichristidis, and M. Schmidt, Macromol. Rapid Commun., 26, 1693 (2005).

35. For reviews, see: 35-37. J. Pyun and K. Matyjaszewski, Chem. Mater., 13, 3436 (2001).

36. J. Pyun, T. Kowalewski, and K. Matyjaszewski, Macromol. Rapid Commun., 24, 1043 (2003).

37. S. Edmondson, V. L. Osborne, and W. T. S. Huck, Chem. Soc. Rev., 33, 14 (2004).

38. M. Ejaz, S. Yamamoto, K. Ohno, Y. Tsujii, and T. Fukuda, Macromolecules, 31, 5934 (1998).

39. S. Yamamoto, M. Ejaz, Y. Tsujii, M. Matsumoto, and T. Fukuda, Macromolecules, 33, 5602 (2000). 
40. S. Yamamoto, M. Ejaz, Y. Tsujii, and T. Fukuda, Macromolecules, 33, 5608 (2000).

41. S. Yamamoto, Y. Tsujii, and T. Fukuda, Macromolecules, 33, 5995 (2000).

42. H. Sakata, M. Kobayashi, H. Otsuka, and A. Takahara, Polym. J., 37, 767 (2005).

43. K.-Y. Beak, Kamigaito, and M. Sawamoto, J. Polym. Sci., Part A: Polym. Chem., 40, 1937 (2002).

44. T. Ando, M. Kamigaito, and M. Sawamoto, Macromolecules, 31, 6708 (1998).

45. Y. Kotani, M. Kato, M. Kamigaito, and M. Sawamoto, Macromolecules, 29, 6979 (1996).

46. J. Ueda, M. Matsuyama, M. Kamigaito, and M. Sawamoto, Macromolecules, 31, 557 (1998).

47. J. Ueda, M. Kamigaito, and M. Sawamoto, Macromolecules,
31, 6762 (1998).

48. K.-Y. Beak, Kamigaito, and M. Sawamoto, Macromolecules, 34, 215 (2001).

49. T. Terashima, M. Kamigaito, K.-Y. Beak, T. Ando, and M. Sawamoto, J. Am. Chem. Soc., 125, 5288 (2003).

50. T. Ando, M. Kamigaito, and M. Sawamoto, Macromolecules, 33, 2819 (2000).

51. H. Takahashi, T. Ando, M. Kamigaito, and M. Sawamoto, Macromolecules, 32, 3820 (1999).

52. S. Hamasaki, M. Kamigaito, and M. Sawamoto, Macromolecules, 35, 2934 (2002).

53. T. Ando, M. Kamigaito, and M. Sawamoto, Macromolecules, 33, 5825 (2000).

54. Y. Watanabe, T. Ando, M. Kamigaito, and M. Sawamoto, Macromolecules, 34, 4370 (2001). 